\title{
AÇÕES AFIRMATIVAS PARA NEGROS: ENTRE A DESCONSTRUÇÃO DAS POLÊMICAS E A TRANSFORMAÇÃO SOCIAL VIA DIREITO
}

\section{Luciano Roberto Gulart Cabral Júnior*}

Resumo: A implantação de ações afirmativas para negros é uma vitória do movimento antirracista. A justiça social de tais medidas ainda é questionada por segmentos sociais, o que revigora a relevância jurídica e científica dos debates sobre a temática. Diante disso, a presente pesquisa qualitativa, fundada no método de abordagem dedutivo e no método de procedimento monográfico, objetiva analisar os argumentos que gravitam as ações afirmativas para negros no Brasil e as leis que instituíram as cotas raciais no ensino federal técnico e superior e no serviço público federal como instrumentos de transformação social.

Palavras-chave: ações afirmativas para negros; cotas raciais; ensino federal superior e técnico; justiça social; serviço público federal.

\section{AFFIRMATIVE ACTIONS FOR BLACKS: BETWEEN THE DECONSTRUCTION OF CONTROVERSIES AND SOCIAL TRANSFORMATION BY THE LAW}

\begin{abstract}
The implementation of affirmative action for blacks is a victory of the anti-racist movement. The social justice of such measures is still questioned by social segments, which invigorates the legal and scientific relevance of the debates on the matter. Given this, the present qualitative research, based on the deductive method of approach and the monographic method of procedure, aims to analyze the arguments about the affirmative actions for blacks in Brazil and the laws that instituted the racial quotas in technical and higher federal education and in the federal public service as instruments of social transformation.
\end{abstract}

Keywords: affirmative actions for blacks; racial quotas; higher and technical federal education; social justice; federal public service.

\section{INTRODUÇÃO}

O histórico da população negra é violentamente marcado pelo sofrimento e pela opressão derivados da escravidão. Validada pelo Estado, a escravidão foi normalizada, naturalizada e reproduzida pelos opressores, excluindo a humanidade pela reificação da população negra.

H. Santos (1997, p. 84) resume que, desde o período colonial brasileiro, somando-se à escravização dos povos originários, passaram-se mais de três séculos de escravização de

\footnotetext{
* Mestre em Direito e Justiça Social no Programa de Pós-Graduação em Direito da Universidade Federal do Rio Grande - FURG. Bacharel em Direito pela Faculdade Anhanguera do Rio Grande. Endereço eletrônico: lucianocabraljunior@hotmail.com.
}

Rev. de Movimentos Sociais e Conflitos | e-ISSN: 2525-9830 | Porto Alegre | v. 4 | n. 2 | p. 01 - 22 | 
pessoas negras. Todavia, no Brasil, ao contrário da escravidão dos demais países, "o que tornou o país possível foi a escravidão. [...] O combustível que foi queimado para legitimar a escravidão colonial, antes de qualquer outro, foi o racismo". Se na Antiguidade a escravidão derivava geralmente de guerras e era desprovida da conotação racial, a escravidão brasileira foi legitimada pela concepção da inferioridade dos negros em relação aos invasores europeus.

Os dados esboçam a dimensão da violência cometida contra os negros escravizados: o tráfico negreiro perdurou por cerca de 320 anos, isto é, durante grande parte da existência do Brasil pós-invasão europeia; o Brasil foi o país que mais recebeu negros escravizados cerca de 4 milhões -, sem contar o número de crianças que nasceram sob o status de escravos; e aproximadamente $10 \%$ das pessoas transportadas não chegavam com vida ao seu destino, o que corresponde a aproximadamente 400 mil pessoas (SANTOS, H., 1997).

O decorrer dos anos trouxe consigo uma reorientação sobre a escravidão. Movimentos abolicionistas posicionaram-se contra a escravidão, fomentando a extinção paulatina dos regimes escravagistas. Entretanto, a efetiva superação da escravidão ocorreu apenas no plano jurídico-formal, haja vista que a opressão cometida contra a população negra permanece até hoje, embora com feições distintas e aparência de não racismo.

$\mathrm{Na}$ luta pelo reconhecimento e pela participação social de forma igualitária, os movimentos antirracistas se empenham na mudança de paradigma, rumo a uma sociedade desprovida de discriminação racial. A busca pela justiça social é notória, justificando-se toda a ação que vise à igualdade racial.

A Constituição brasileira de 1988, resgatando juridicamente a democracia no Brasil, representou um passo decisivo para a luta antirracista, o que foi seguido pela Lei $\mathrm{n}^{\circ} 12.711$, de 29 de agosto de 2012, e pela Lei $n^{\circ}$ 12.990, de 9 de junho de 2014, que instituíram, respectivamente, as ações afirmativas para negros no ensino técnico e superior federais e no serviço público federal. Se, por um lado, a edição de tais normas jurídicas foi aprovada e aplaudida por setores sociais, por outro lado foi alvo de desqualificações por setores conservadores. Tal dilema ensejou a provocação do Supremo Tribunal Federal para o controle concentrado de constitucionalidade dessas duas leis.

Nesse cenário, a presente pesquisa qualitativa, escorada na bibliografia e na legislação, objetiva analisar os argumentos que gravitam as ações afirmativas para negros no Brasil e as leis que instituíram as cotas raciais no ensino federal técnico e superior e no serviço público federal como instrumentos de transformação social. 
Para tanto, o artigo é estruturado da seguinte maneira: inicialmente, busca-se detalhar termos e definições relevantes para a base que acompanha o debate teórico sobre ações afirmativas para negros; logo após, discorre-se sobre as polêmicas em torno das ações afirmativas para negros no Brasil; e, derradeiramente, analisam-se as leis das ações afirmativas para negros no ensino federal técnico e superior e no serviço público federal e como elas são estruturadas na concretização da justiça social.

\section{POPULAÇÃO NEGRA, PRECONCEITO RACIAL, DISCRIMINAÇÃO RACIAL E RACISMO}

O Estatuto da Igualdade Racial, Lei no 12.288, de 20 de julho de 2010 (BRASIL, 2010), determina que, para seus fins, considera-se população negra "o conjunto de pessoas que se autodeclaram pretas e pardas, conforme o quesito cor ou raça usado pela Fundação Instituto Brasileiro de Geografia e Estatística (IBGE), ou que adotam autodefinição análoga" (artigo $1^{\circ}$, caput, inciso IV). O Estatuto define, portanto, que negros são tanto as pessoas pardas quanto as pretas.

Com efeito, conforme S. Santos (2007), não existem estatisticamente diferenças raciais substanciais entre as situações desfavoráveis que envolvem os pretos e pardos Minhoto (2013, p. 12) alude que “o 'pardo' é socialmente visto como um preto ou, pelo menos, como um não-branco". ${ }^{1}$ De outro ângulo, é significativamente perceptível a diferença quando são defrontadas as vantagens obtidas pelos brancos e não usufruídas pelos pretos e pardos:

De um lado, pretos e pardos estão muito próximos em termos de obtenção ou exclusão de direitos legítimos e constitucionalmente garantidos e, de outro lado, estão bem distantes dos direitos e vantagens auferidos pelos brancos no Brasil. Diante disso juntamos aquelas duas categorias e formamos o grupo racial negros, visto que para nós há um denominador comum entre "pardos" e "pretos": a discriminação racial que ambos sofrem no plano sociológico. Ou seja, são as

\footnotetext{
${ }^{1}$ Francklin (2017) disserta que o "colorismo" (ou "pigmentocracia") refere-se à diferenciação social estabelecida em razão da pigmentação da pele de pessoas negras, em que a tonalidade de pele mais clara é mais aceita no convívio social do que a tonalidade de pele mais escura. Ou seja, há um escalonamento da tendência à incidência da discriminação racial que depende do fenótipo: os traços próximos ao padrão fenotípico eurocêntrico, como a pele mais clara, o nariz fino e o cabelo liso ou alisado, são os requisitados para a aceitação social dos negros. Mesmo assim, essa menor reprovação social não corresponde ao acesso igualitário aos privilégios obtidos pelas pessoas brancas. Significa dizer que a aludida aceitação social não nega - ao contrário, reforça - o racismo e a desigualdade racial que os pardos, assim como os pretos, também sofrem em relação aos brancos.
}

Rev. de Movimentos Sociais e Conflitos | e-ISSN: 2525-9830 | Porto Alegre | v. 4 | n. 2 | p. 01 - 22 | Jul/Dez. 2018 
dificuldades comuns proporcionadas pelo racismo às populações pretas e pardas que justificam unirmos as categorias preto e pardo da taxonomia racial estabelecida pelo IBGE, formando o grupo racial negros (SANTOS, S., 2007, p. 21-22).

A terminologia "afrodescendente" não é suficiente para designar a população negra. Primeiro, porque é tecnicamente imprecisa, dada a sua excessiva abrangência a todos que possuem algum antepassado africano. Segundo, pois se prende mais a um discurso politicamente correto do que a qualquer outro fator (MINHOTO, 2013). E terceiro, porque a origem da humanidade é atribuída à África, de modo que todos são afrodescendentes.

O censo demográfico realizado pelo Instituto Brasileiro de Geografia e Estatística (IBGE), no ano de 2010, caracterizou a sociedade brasileira como composta por 91 milhões de pessoas que se classificaram como brancas, correspondendo a 47,7\% em termos proporcionais. Quanto aos negros, cerca de 82 milhões de pessoas se declararam como de cor parda, o equivalente a 43,1\%, e 15 milhões de cor preta, representando 7,6\% do total. Os demais se classificaram como de cor amarela (quase 2 milhões) ou como indígenas (817 mil) (IBGE, 2012, p. 62).

Portanto, 50,7\% dos brasileiros são negros (pretos e pardos). Todavia, ainda que reflita uma pequena demonstração do ambiente que retrata, a desigualdade racial $^{2}$ brasileira é verificada pelos demais dados colhidos pelo IBGE (2012): o analfabetismo entre as pessoas de 15 anos de idade ou mais atinge 5,9\% dos brancos e 27,4\% dos negros (14,4\% para pretos e 13,0\% para pardos); o ensino superior, na faixa etária de 15 a 24 anos de idade, é acessado por $31,1 \%$ dos brancos e por $26,2 \%$ dos negros (12,8\% dos pretos e $13,4 \%$ dos pardos); e a razão do rendimento domiciliar per capita aponta que os brancos percebem rendimentos 2,0 vezes maiores do que os rendimentos dos pretos e 2,1 vezes maiores do que os rendimentos dos pardos no Sudeste, e nas demais regiões do Brasil os brancos percebem rendimentos 1,7 vez maior do que os rendimentos dos pretos e 1,8 vez maior do que os rendimentos dos pardos.

N. Gomes (2005) disserta que, dependendo do contexto, "raça" pode ser uma terminologia aceita ou rejeitada. Se usada para justificar a opressão, a dominação, a discriminação em relação à população negra, deve ser rechaçada; se se entender que o abandono do termo "raça" não resolve o racismo e a concepção sobre ele, deve ser aceito o

\footnotetext{
${ }^{2}$ Desigualdade racial é "toda situação injustificada de diferenciação de acesso e fruição de bens, serviços e oportunidades, nas esferas pública e privada, em virtude de raça, cor, descendência ou origem nacional ou étnica" (artigo $1^{\circ}$, caput, inciso II, do Estatuto da Igualdade Racial) (BRASIL, 2010).
} 
seu uso, desde que afastado do sentido biológico. Efetivamente, a raça não é dada pela natureza (critério biológico), mas corresponde a uma construção social, política e cultural, artifício de controle nas relações sociais e de poder ${ }^{3}$. Alguns preferem "etnia" ao termo "raça", referindo que o primeiro, ao contrário do segundo, não é associado ao determinismo biológico que divide a humanidade em raças superiores e inferiores ${ }^{4}$. Há também quem se refira ao termo "étnico-racial". Entretanto, o termo "raça" ainda é difundido no senso comum porque "raça ainda é o termo que consegue dar a dimensão mais próxima da verdadeira discriminação contra os negros, ou melhor, do que é o racismo que afetas as pessoas negras da nossa sociedade" (GOMES, N., 2005, p. 45, grifo no original).

Preconceito racial, discriminação racial e racismo não são sinônimos. O preconceito racial são ideias, pensamentos e representações sociais negativos, construídos aprioristicamente e assentados em generalizações estigmatizantes, contra sujeitos e grupos inferiorizados por pertencerem a determinada etnia. A discriminação racial é a materialização de atitudes (ações ou omissões) preconceituosas, violando direitos das vítimas que integram a raça discriminada ${ }^{5}$. O racismo é uma ideologia que sustenta a hierarquia entre grupos raciais baseada na crença de que determinado grupo social é inferior por aspectos de ordem moral, física, intelectual, cultural (JACCOUD; BEGHIN, 2002; RIOS, 2009; SANTOS, H., 2001; SILVA JR., 2001). Nesse diapasão, Guimarães (2009, p. 215) complementa:

Racismo pode, ademais, referir-se não apenas a doutrinas, mas a atitudes (tratar diferencialmente as pessoas de outras raças e culturas, ou seja, discriminar) e a preferências (hierarquizar gostos e valores estéticos de acordo com a ideia de raça ou

\footnotetext{
${ }^{3}$ O preâmbulo da Convenção Internacional sobre a Eliminação de todas as Formas de Discriminação Racial dispõe: "qualquer doutrina de superioridade baseada em diferenças raciais é cientificamente falsa, moralmente condenável, socialmente injusta e perigosa, em que, não existe justificação para a discriminação racial, em teoria ou na prática, em lugar algum" (BRASIL, 1969).

${ }^{4}$ H. Santos (2001, p. 83-84, grifos no original) comenta que "quando temos um conjunto humano que possui as mesmas características físicas, originária de antepassados que são comuns, podemos falar que estamos diante de um grupo racial". No entanto, o termo raça está caindo em desuso nas ciências porque não existem raças, do ponto de vista biológico, na humanidade. Deve prevalecer - prossegue o autor -, então, a ideia de etnia: "quando se fala em grupo étnico, a idéia que se tem é de um conjunto humano com sólido sentido de união e pertença (as pessoas sentem pertencerem ao mesmo grupo). Tem-se a mesma cultura; o que envolve a história, o idioma, a tradição com os seus valores - todos eles comuns. A idéia de raça é mais árida, pois somos levados a pensar em aspectos físicos".

${ }^{5}$ Baseado no texto expresso do artigo I, 1, da Convenção Internacional sobre a Eliminação de todas as Formas de Discriminação Racial (BRASIL, 1969), o Estatuto da Igualdade Racial estabelece que "discriminação racial ou étnico-racial" é “toda distinção, exclusão, restrição ou preferência baseada em raça, cor, descendência ou origem nacional ou étnica que tenha por objeto anular ou restringir o reconhecimento, gozo ou exercício, em igualdade de condições, de direitos humanos e liberdades fundamentais nos campos político, econômico, social, cultural ou em qualquer outro campo da vida pública ou privada" (artigo $1^{\circ}$, caput, inciso I) (BRASIL, 2010).
}

Rev. de Movimentos Sociais e Conflitos | e-ISSN: 2525-9830 | Porto Alegre | v. 4 | n. 2 | p. 01 - 22 | Jul/Dez. 2018 
de cultura, de modo a inferiorizar, sistematicamente, características fenotípicas raciais ou culturais).

É importante destacar a diferença entre a discriminação direta e a indireta. Nem sempre a discriminação racial deriva de atos concretos, expressos, explícitos, como ocorre na discriminação direta. A discriminação também assume feições aparentemente neutras, inofensivas, em geral consideradas legítimas, ocultando dissimuladamente o real potencial discriminatório, caso em que é considerada como indireta. A discriminação indireta é desvelada, por exemplo, quando índices indicam que a população negra é socioeconomicamente desfavorecida, bem como quando se está diante do racismo institucionalizado, que implica a distribuição de benefícios ou recursos que, sem considerar a desigualdade racial, acaba por aumentá-la (JACCOUD; BEGHIN, 2002).

Jaccoud e Beghin (2002) expõem que o combate ao preconceito racial ocorre por intermédio de políticas persuasivas ou valorativas, visando ao reconhecimento e à valorização da população negra. Por sua vez, a discriminação direta é contra-atacada via políticas repressivas, a exemplo do sistema penal, e a discriminação indireta é refreada pelas políticas de ação afirmativa. O racismo, constituindo-se tanto de ideologia quanto de práticas materiais, deve ser enfrentado por políticas persuasivas e valorativas, políticas repressivas e políticas de ação afirmativa.

Quanto à repressão legislativa, destaque-se o crime de injúria racial $^{6}$, que prevê a pena de reclusão, de um a três anos e multa, a quem ofender a dignidade ou o decoro de outrem, utilizando-se de elementos referentes à raça, cor ou etnia (bem como à religião, origem ou condição de pessoa idosa ou portadora de deficiência). Outrossim, a Lei $n^{\circ}$ 7.716, de 5 de janeiro de 1989, que "define os crimes resultantes de preconceito de raça ou de cor" (BRASIL, 1989), estabelece, segundo o seu artigo $1^{\circ}$, que "serão punidos, na forma desta Lei, os crimes resultantes de discriminação ou preconceito de raça, cor, etnia, religião ou procedência nacional" ${ }^{, 7}$. Entre os delitos por ela tipificados, sublinhe-se o disposto no artigo

\footnotetext{
${ }^{6}$ A injúria racial foi instituída pela Lei $\mathrm{n}^{\circ}$ 9.459, de 13 de maio de 1997 , que incluiu o $\S 3^{\circ}$ ao artigo 140 do Código Penal (BRASIL, 1940).

${ }^{7}$ Redação dada pela Lei no 9.459 , de 13 de maio de 1997.
}

Rev. de Movimentos Sociais e Conflitos | e-ISSN: 2525-9830 | Porto Alegre | v. 4 | n. 2 | p. 01 - 22 | 
20, caput $^{8}$ : "Praticar, induzir ou incitar a discriminação ou preconceito de raça, cor, etnia, religião ou procedência nacional": "Pena: reclusão de um a três anos e multa". 9 "

Tudo isso se consubstancia em mecanismos de enfrentamento ao racismo secular no Brasil. Por aqui nunca houve efetivamente uma integração pacífica entre negros e brancos, o que não foi superado sequer com o fim do sistema escravagista (RODRIGUES; ROSCHILDT, 2011). Fernandes (1978) e N. Gomes (2005) explicam que a democracia racial brasileira é um mito porque concebe a inexistência de desigualdade entre brancos e negros, como consequência do racismo. Tal engodo pretende falsear a realidade, com pretensão ideológica de negar a discriminação racial e afirmar a igualdade de oportunidade e de tratamento entre negros e brancos, perpetuando o racismo contra os negros. De outra ponta, o mito da democracia racial abastece o estereótipo de que os negros são inerentemente mais incapazes e menos inteligentes do que os brancos, haja vista que os centros de poder e as ocupações valorizadas socialmente são ocupados por brancos.

\section{AS POLÊMICAS EM TORNO DAS AÇÕES AFIRMATIVAS PARA NEGROS}

O postulado da igualdade formal, que presume absolutamente que todos são iguais e possuem as mesmas condições de ascensão social, não é compatível com a realidade de desigualdade socioeconômica e racial do Brasil. A construção de uma sociedade justa e solidária não ratifica a igualdade formal como fundamento da omissão estatal para o enfrentamento efetivo das desigualdades.

Diante isso, as ações afirmativas ${ }^{10}$ (também denominadas discriminações positivas) são políticas públicas e privadas que objetivam a concretização do princípio da igualdade material ou substancial, a eliminação da discriminação e a correção dos respectivos efeitos negativos que ainda perduram. Não se restringem à proibição e à reparação após a ocorrência do dano, pois buscam a transformação social combatendo as desigualdades e promovendo a

\footnotetext{
${ }^{8}$ Redação dada pela Lei no 9.459, de 13 de maio de 1997.

9 Além disso, a Constituição Brasileira define que a prática de racismo é crime inafiançável e imprescritível (artigo $5^{\circ}$, inciso XLII), e o Superior Tribunal de Justiça reconheceu que a injúria racial, por ser delito no cenário do racismo, também é inafiançável e imprescritível (Superior Tribunal de Justiça. Agravo Regimental no Agravo em Recurso Especial nº 686965 / DF. Sexta Turma. Relator Ericson Maranho. Julgado em 18.08.2015).

${ }^{10}$ O surgimento das ações afirmativas ocorreu nos Estados Unidos, em 1960, através da imposição de contratação pelos empregadores de pessoas negras, diante da marginalização socioeconômica que estas sofriam no país (GOMES, J., 2005; RODRIGUES; ROSCHILDT, 2011).
}

Rev. de Movimentos Sociais e Conflitos | e-ISSN: 2525-9830 | Porto Alegre | v. 4 | n. 2 | p. 01 - 22 | Jul/Dez. 2018 
diversidade e a representatividade do grupo discriminado nos setores públicos e privados (GOMES, J., 2005).

As ações afirmativas conferem tratamento preferencial e favorável àqueles que são preteridos e desfavorecidos nas relações sociais, com o escopo de combater a exclusão social e igualar as posições antagônicas. São temporárias e focalizadas, redistributivas e compensatórias, espontâneas ou compulsórias (JACCOUD; BEGHIN, 2002). Fundamentalmente, "as políticas de ação afirmativa ancoram-se em uma crítica ao princípio da igualdade formal perante a lei e organizam-se em torno de uma demanda concreta de igualdade - a igualdade de oportunidade" (JACCOUD; BEGHIN, 2002, p. 46). Assim sendo, a assimetria social entre brancos e negros justifica as ações afirmativas, dado que permite "tratar desiguais de forma desigual com o objetivo de promover a igualdade de oportunidades hoje negada aos grupos racialmente discriminados" (JACCOUD; BEGHIN, 2002, p. 46). ${ }^{11}$

Contudo, não há unanimidade sobre os benefícios trazidos pelas ações afirmativas para negros. Guimarães (2009) elaborou um quadro que indica os principais argumentos contrários às ações afirmativas para negros no Brasil e, paralelamente, apresenta o contraponto dos argumentos favoráveis a elas, conforme a Tabela 1.

Tabela 1 - Argumentos no debate brasileiro sobre as ações afirmativas para negros, segundo Guimarães

\begin{tabular}{l|l}
\hline \multicolumn{1}{c|}{ CONTRA } & \multicolumn{1}{c}{ A FAVOR } \\
\hline $\begin{array}{l}\text { Significam o reconhecimento de raças e } \\
\text { distinções de raças no Brasil e isso contraria o } \\
\text { credo brasileiro de que somos um só povo, uma } \\
\text { só nação. }\end{array}$ & $\begin{array}{l}\text { Raça é um dos critérios reais, embora não } \\
\text { declarados, de discriminação, utilizados em toda a } \\
\text { sociedade brasileira; para combatê-lo, é mister } \\
\text { reconhecer sua existência. }\end{array}$ \\
\hline $\begin{array}{l}\text { Não se pode discriminar positivamente, no Brasil, } \\
\text { porque não há limites rígidos e objetivos entre as }\end{array}$ & $\begin{array}{l}\text { Esses limites não existem em nenhum lugar; o } \\
\text { que conta, na discriminação, tanto positiva quanto } \\
\text { raças. }\end{array}$ \\
$\begin{array}{l}\text { negativa, é a construção social da raça } \\
\text { identificação racial). }\end{array}$ \\
$\begin{array}{l}\text { A indefinição dos limites raciais, no Brasil, ou a } \\
\text { ausência de tradições de identificação racial daria } \\
\text { margem a que oportunistas se aproveitassem da } \\
\text { situação. }\end{array}$ & $\begin{array}{l}\text { Esse risco é real. Políticas de ação afirmativa } \\
\text { requerem reconhecimento oficial das identidades } \\
\text { raciais. No entanto, a discriminação positiva, por } \\
\text { ser pontual, não pode reverter, a curto prazo, a } \\
\text { estruturação de discriminação existente; por isso, } \\
\text { o oportunismo esperado seria mínimo. }\end{array}$ \\
\hline $\begin{array}{l}\text { Medidas universalistas teriam o mesmo efeito. } \\
\text { Medidas universalistas não rompem os } \\
\text { mecanismos inerciais de exclusão. }\end{array}$ \\
\hline
\end{tabular}

${ }^{11}$ No mesmo sentido é a definição de ações afirmativas do Estatuto da Igualdade Racial: "programas e medidas especiais adotados pelo Estado e pela iniciativa privada para a correção das desigualdades raciais e para a promoção da igualdade de oportunidades" (artigo 1º, caput, inciso VI) (BRASIL, 2010).

Rev. de Movimentos Sociais e Conflitos | e-ISSN: 2525-9830 | Porto Alegre | v. 4 | n. 2 | p. 01 - 22 | Jul/Dez. 2018 


\begin{tabular}{l|l}
\hline $\begin{array}{l}\text { Não há, na sociedade brasileira, consenso sobre a } \\
\text { desigualdade social provocada por diferenças de } \\
\text { cor e raça. }\end{array}$ & $\begin{array}{l}\text { Tais políticas poderiam ajudar a legitimar esse } \\
\text { consenso. }\end{array}$ \\
\hline $\begin{array}{l}\text { Reforçariam práticas de privilegiamento e de } \\
\text { desigualdade hierárquica. }\end{array}$ & $\begin{array}{l}\text { Teriam o efeito contrário: ao inverter a } \\
\text { desigualdade, poriam a nu o absurdo da ordem } \\
\text { estamental. }\end{array}$ \\
\hline $\begin{array}{l}\text { Ferem os direitos constitucionais daqueles que } \\
\text { passam a ser excluídos em consequência de sua } \\
\text { aplicação. }\end{array}$ & $\begin{array}{l}\text { Não há base legal para demonstrar a a } \\
\text { inconstitucionalidade de políticas de ação } \\
\text { afirmativa. }\end{array}$ \\
\hline
\end{tabular}

Fonte: Guimarães (2009, p. 192-193).

H. Santos (1997) também resume quatro argumentos básicos - aliás, os mesmos expostos por Rodrigues e Roschildt (2011) -, contrários e favoráveis, no que concerne à política de ações afirmativas para negros, a partir dos quais foi elaborada a Tabela 2.

Tabela 2 - Argumentos no debate brasileiro sobre as ações afirmativas para negros, segundo H. Santos

\begin{tabular}{l|l}
\hline \multicolumn{1}{c|}{ CONTRA } & \multicolumn{1}{c}{ A FAVOR } \\
\hline $\begin{array}{l}\text { A política de ação afirmativa fere o princípio da } \\
\text { isonomia, que pede tratamento igual a todos. }\end{array}$ & $\begin{array}{l}\text { Não é possível combater a enorme diferença entre } \\
\text { brancos e negros no Brasil a partir de políticas } \\
\text { universalistas. Somente se tratando } \\
\text { diferentemente os desiguais pode-se alcançar } \\
\text { maior igualdade entre os grupos. }\end{array}$ \\
\hline $\begin{array}{l}\text { As sociedades contemporâneas não podem abrir } \\
\text { mão da excelência; no mundo de alta } \\
\text { competitividade, essa capacidade pessoal revela- } \\
\text { se fundamental. }\end{array}$ & $\begin{array}{l}\text { Esso permitirá não apenas incrementar o processo } \\
\text { de inclusão da população negra na sociedade } \\
\text { como possibilitará ao país ganhar em excelência, } \\
\text { aumentando o número de pessoas capazes de } \\
\text { desenvolver plenamente suas potencialidades. } \\
\text { Hoje, somente um estrato pequeno da população } \\
\text { está capacitado a competir e a desenvolver seus } \\
\text { talentos. }\end{array}$ \\
\hline $\begin{array}{l}\text { A verdadeira questão a ser enfrentada é a a a } \\
\text { econômica; deve-se desenvolver políticas } \\
\text { voltadas para os pobres, esquecendo o aspecto }\end{array}$ & $\begin{array}{l}\text { É necessário implementar uma política específica } \\
\text { para os negros independentemente da política de } \\
\text { combate à pobreza }\end{array}$ \\
\hline
\end{tabular}

\footnotetext{
${ }^{12}$ Bento (2005, p. 172) elucida que os negros não devem se sentir humilhados diante da fruição das cotas: "se os brancos têm sobrevivido ao longo de séculos à humilhação de viver sob um sistema que os privilegia, se têm sobrevivido às inquietações éticas de ser preferenciado em todo e qualquer espaço de poder silenciosamente preservado em nosso país, os negros poderão sobreviver às cotas, conquistadas através de lutas do movimento social".

${ }^{13}$ H. Santos (1997, p. 33) explica que políticas públicas contra a pobreza não combateriam diretamente a desigualdade racial, pois até os negros não pobres são afetados pela discriminação racial: "o argumento de que devemos investir apenas nos mais pobres, e que essa seria a maneira adequada, e não privilegiar sob o aspecto racial, eu quero dizer, que no Brasil temos uma pobreza que é uma pobreza cristalizada, que é uma pobreza secular, ou seja, os investimentos devem ser feitos de uma outra forma. O investimento na pobreza, exclusivamente na pobreza, ele não conseguirá alavancar, por exemplo, os setores negros, que são setores que,
}

\footnotetext{
Rev. de Movimentos Sociais e Conflitos | e-ISSN: 2525-9830 | Porto Alegre | v. 4 | n. 2 | p. 01 - 22 | Jul/Dez. 2018
} 


\begin{tabular}{l|l}
\hline racial. & $\begin{array}{l}\text { de marginalização e baixa auto-estima, uma } \\
\text { política voltada aos mais pobres sem articulação } \\
\text { com a questão racial não conseguirá alavancar os } \\
\text { segmentos negros da população. }\end{array}$ \\
\hline $\begin{array}{l}\text { O processo de miscigenação que marcou a } \\
\text { história do país torna muito difícil definir quem é } \\
\text { negro e quem não é negro, o que impediria a a } \\
\text { adoção de critérios claros de inclusão nos grupos } \\
\text { beneficiados. }\end{array}$ & $\begin{array}{l}\text { As políticas compensatórias ligadas à raça devem } \\
\text { atingir tanto pretos como pardos, pois os dados } \\
\text { socioeconômicos demonstram que as dificuldades } \\
\text { educacionais e econômicas são similares para os } \\
\text { dois grupos. }\end{array}$ \\
\hline
\end{tabular}

Fonte: Jaccoud e Beghin (2002, p. 49-51), baseadas em H. Santos (1997).

Pontua-se que não se sustenta o argumento que invalida as ações afirmativas para os negros com base na ideia de que políticas públicas para os pobres seriam mais eficazes e justas. Como não é possível se combater o racismo unicamente por políticas universalistas, valorativas ou repressivas, a inversão do processo histórico de exclusão requer as ações afirmativas. As ações de combate à pobreza, isoladamente, não são capazes de provocar uma alteração substancial na desigualdade racial vigente na sociedade brasileira (JACCOUD; BEGHIN, 2002). Há processos de exclusão social relacionados à questão étnica que são independentes da questão socioeconômica, razão pela qual a negação das ações afirmativas para negros mantém a atual vigência das "cotas" de praticamente 100\% para brancos (BENTO, 2005).

Reforçando a necessidade de atuação conjunta entre políticas universalistas de combate à pobreza e políticas diferencialistas, Jaccoud e Beghin (2002) atentam que as ações afirmativas não serão uniformes para toda a população negra, podendo de fato beneficiar os negros mais capacitados para a disputa dos espaços de poder e as áreas sociais mais privilegiadas entre as desprivilegiadas. Mesmo assim, Minhoto (2013 p. 135) contraargumenta a ideia que invalida as ações afirmativas diante do beneficiamento de privilegiados entre os desprivilegiados com o seguinte exemplo: "não conceber o benefício da passagem de ônibus gratuita olhando para os $1 \%$ de idosos ricos, assim, não seria justo e nem razoável com os outros indivíduos pobres e de classe média pertencentes a tal faixa de idade". Somado a isso, é razoável concluir que somente os idosos que necessitem do transporte coletivo - em geral, a população mais pobre - se beneficiarão da gratuidade. Com isso, "imaginar que um idoso rico, com carro, prefira o ônibus só para gozar do benefício ofertado pelo Estado é

além de empobrecidos, são historicamente marginalizados: que trabalham com uma auto-estima extremamente baixa".

Rev. de Movimentos Sociais e Conflitos | e-ISSN: 2525-9830 | Porto Alegre | v. 4 | n. 2 | p. 01 - 22 | Jul/Dez. 2018 
raciocínio excessivamente zeloso e, bem de se ver, voltado à hipótese rigorosamente pontual" (MINHOTO, 2013, p. 135).

Sobre a relação meritocracia e ações afirmativas, Guimarães (2009) comenta que as ações afirmativas almejam a correção dos mecanismos de seleção por mérito, e não a sua eliminação. As ações afirmativas são focalizadas e destinadas àqueles âmbitos em que o acesso do negro é comprovadamente obstaculizado. Nas demais searas, não atingidas pela discriminação étnica, as medidas universalistas são as adequadas. Não é o mérito como principal critério de ingresso que é suprimido; ao contrário, tendo em vista que corrompido pelas desigualdades raciais e de classe, corrige-se tal critério por intermédio das políticas compensatórias, motivando a desracialização e a desetnização da elite, que atualmente é branca.

Guimarães (2009, p. 203-204) inclusive diz que as ações afirmativas se prestam a "uma defesa da legitimidade do mérito e uma tentativa de livrá-lo da contaminação de acidentes raciais, étnicos ou sexuais; sua virtude está em procurar evitar que mecanismos meritocráticos acabem por concentrar no topo indivíduos de uma mesma raça, etnia ou sexo". Nessa linha de raciocínio, a ampliação dos participantes do processo meritocrático oxigenaria as elites intelectuais e econômicas, tornando-as, aí sim, representativas do resultado de um processo competitivo justo entre todos os membros da sociedade, aos quais se disponibilizou efetiva igualdade de oportunidades.

Observa-se, malgrado, que a própria noção de meritocracia é carregada de subjetivismos e de caracteres ideológicos, morais, sociológicos, antropológicos e psicológicos (MINHOTO, 2013). A meritocracia é individualista e desconsidera fatores socialmente relevantes que desequilibram a competitividade que lhe é ínsita. E sem a igualdade de oportunidades na base, a estrutura meritocrática desaba diante da ausência do postulado abstrato que lhe deveria sustentar: a eleição dos melhores segundo a avaliação do seu próprio desempenho. À medida que os negros são tolhidos das relações sociais destinadas à aquisição de competência técnica para a aferição do mérito, o processo de seleção social é viciado na origem. As ações afirmativas objetivam atuar nesse desequilíbrio para que a igualdade de oportunidades prevaleça.

Noutro giro, Martins (2005, p. 195) assevera que sustentar que o Brasil é um país mestiço e, por conta disso, torna-se impossível se distinguir negros e brancos, descortina uma postura típica do "racismo à brasileira, pois a dificuldade não é quanto a se definir um branco 
no Brasil. Com base nessa linha argumentação, pode-se notar o apagamento da identidade negra como uma realidade positiva". As ações afirmativas, assim, possuem mais esta vantagem: consolidar a existência e a identidade dos sujeitos vítimas de discriminação racial (GUIMARÃES, 2009). ${ }^{14}$

De outro ângulo, o argumento que justifica as ações afirmativas em relação aos pretos, mas as nega para os pardos, serve de dissuasão da população negra, separando e criando subgrupos em um conjunto populacional que comunga mais características comuns do que dessemelhantes. Notadamente um instrumento de divisão de um segmento populacional já segredado. Por outro lado, essa perspectiva situa os pardos em um limbo identitário: não são pretos nem são brancos; não são privilegiados como os brancos são, mas também não podem ser sujeitos das ações afirmativas destinadas exclusivamente aos pretos.

Concluir que as ações afirmativas para negros intensificam o binarismo branco e negro tem o sentido ideológico de materializar discursivamente o humanismo individualista abstrato, desvinculado da realidade social racista da sociedade brasileira. As ações afirmativas somente asseveram a dualidade branco e negro para aqueles que creem equivocadamente na existência de uma sociedade não racista - embora estejam apoiados em um discurso racista de manutenção dos privilégios a favor dos brancos. Quem percebe o racismo institucionalizado compreende que as ações afirmativas são políticas que almejam a redução da desigualdade racial.

Outra tese contrária às ações afirmativas é lembrada por Minhoto (2013), a qual lhes imputaria a impossibilidade de um critério objetivo para a avaliação de quem é efetivamente negro, o que não acontece nas ações afirmativas para os idosos, as mulheres e os pobres. Tal objetividade, entretanto, existe, ainda que menos visível para alguns. Conforme Guimarães (2009, p. 191), “a identidade negra varia regionalmente e, portanto, um 'negro na Bahia' pode ter características fenotípicas diferentes das de um 'negro de Porto Alegre'. Não há problemas em que a definição de raça ou de cor varie regionalmente". A raça não se liga a critérios puramente biológicos, mas é retrato da construção social que demarca territórios de discriminação e exclusão.

\footnotetext{
${ }^{14}$ Com efeito, Munanga (1996) afirma que a identidade "afro-brasileira" existe culturalmente, e a sua resistência histórica é prova disso. Por conseguinte, é preciso a tomada de consciência política da existência dessa identidade cultural que contribuiu - e contribui - para a construção do país (seja culturalmente, seja economicamente pelo trabalho gratuito e escravizado), de modo que ela também deve usufruir do produto político e socioeconômico gerado no Brasil.
}

Rev. de Movimentos Sociais e Conflitos | e-ISSN: 2525-9830 | Porto Alegre | v. 4 | n. 2 | p. 01 - 22 | 
O processo de seleção dos beneficiários das ações afirmativas para negros é delicado e exige uma atenção especial, tanto para evitar fraudes daqueles que não são negros e, com isso, beneficiarem-se ilegitimamente, quanto para considerar como não negro alguém que individual e socialmente é assim considerado, acarretando a negação da identidade reconhecida e o aval quanto ao racismo perpetrado. As comissões instaladas para a verificação das autodeclarações ${ }^{15}$ devem ter o cuidado para não negar a condição de negro àqueles que o são. Os mais propensos a serem essas vítimas são os pardos, visto que se subsumem à hipótese que vincula as ações afirmativas unicamente aos pretos e não aos pardos.

Sobre as manifestações contrárias às ações afirmativas, Bertúlio (2012, p. 141) diz:

\begin{abstract}
Os argumentos e valores produzidos e reproduzidos no período escravista de nossa história, sob os auspícios e as determinações do Direito e do Estado, repetem-se sem qualquer atualização. Para nossa sociedade, o racismo e o ideário que o promove não têm tempo histórico definido - estavam lá como estão cá. Os movimentos contrários ao abolicionismo, como os movimentos contrários às políticas públicas com recorte racial para a população negra, têm as mesmas escusas, os mesmos argumentos de pseudocuidado com aquele público, de forma a "prevenir" racismos, rebeliões ou discriminações, ou seja, é preciso ter cautela com os negros libertos, como se deve ter cuidado com os negros na universidade, cuidado com a possibilidade desse grupo exercer posições de poder na sociedade. As figuras e justificativas se conformam e se confundem no tempo - séculos XIX ou XX ou hoje, XXI.
\end{abstract}

A posição contrária às ações afirmativas para negros, supostamente ancorada em fundamentos jurídicos, reproduz o racismo impregnado na sociedade brasileira por meio de argumentos abstratos que são dissociados da realidade racista brasileira e que, portanto, exige a intervenção estatal para a concretização do princípio da solidariedade e da justiça social, previstos na Constituição brasileira. E como a educação e o trabalho são direitos fundamentais sociais (artigo $6^{\circ}$ da Constituição brasileira), a importância da ação afirmativa para negros nessas duas áreas se avulta. Até porque, a igualdade material preconiza, nas difundidas palavras de B. Santos (2003, p. 458) - no mesmo sentido da clássica lição atribuída a Rui Barbosa -, que "temos o direito a ser iguais quando a diferença nos inferioriza; temos o direito a ser diferentes quando a igualdade nos descaracteriza".

${ }^{15}$ O Supremo Tribunal Federal, na Arguição de Descumprimento de Preceito Fundamental no 186 (BRASIL, 2012b) e na Ação Declaratória de Constitucionalidade $n^{\circ} 41$ (BRASIL, 2017), teve a oportunidade de se manifestar pela constitucionalidade da autoidentificação e da heteroidentificação (identificação por terceiros, que compõem uma comissão) como instrumentos utilizados para a avaliação do critério étnico-racial, baseada no fenótipo. Tal posição também se propõe a combater as condutas fraudulentas. No caso de dúvida razoável sobre o fenótipo, a ADC 41 fixou o entendimento de que deve prevalecer a autodeclaração racial do candidato.

Rev. de Movimentos Sociais e Conflitos | e-ISSN: 2525-9830 | Porto Alegre | v. 4 | n. 2 | p. 01 - 22 | Jul/Dez. 2018 


\section{JUSTIÇA SOCIAL E AÇÕES AFIRMATIVAS PARA NEGROS NO DIREITO BRASILEIRO}

Historicamente, o Direito é usado pelas classes detentoras do poder para a manutenção e imposição da ideologia dominante. A condição de sub-humanidade que o regime escravagista impôs aos negros é exemplo de como a lei também pode servir para legitimar ações que contradigam a dignidade humana. É o caso da legislação escravagista do período colonial brasileiro, que não considerava o escravo como pessoa, atribuindo-lhe o status de coisa, de bem comercializável e propriedade de outrem (BERTÚLIO, 2012).

O regime escravagista não preparou o negro escravizado nem o liberto para o trabalho "livre"; pelo contrário, deformou-o, impossibilitando-o de competir na sociedade de classes (FERNANDES, 1978). Ou seja, a abolição formal da escravatura ${ }^{16}$, ocasionada pela Lei Áurea - Lei Imperial $n^{\circ} 3.353$, de 13 de maio de 1888 -, não extinguiu a condenação social do negro à imobilidade econômica e educacional, e a acumulação desses prejuízos é sentida até hoje pela população negra (SANTOS, H., 1997).

Daí o aumento da importância de normas jurídicas antirracistas, ratificando o fato de também ser possível utilizar o Direito para o enfrentamento da opressão ${ }^{17}$. No plano internacional, gize-se a Convenção Internacional sobre a Eliminação de todas as Formas de Discriminação Racial, adotada pelas Nações Unidas, de 1965, ratificada pelo Brasil em 1968 e promulgada neste país pelo Decreto $\mathrm{n}^{\circ}$ 65.810, de 8 de dezembro de 1969 (BRASIL, 1969).

A Convenção Internacional sobre a Eliminação de todas as Formas de Discriminação Racial estabelece que os Estados repudiam a discriminação racial e comprometem-se a eliminá-la. A Convenção, outrossim, ampara a edição de ações afirmativas para negros:

Artigo I, 4: Não serão consideradas discriminação racial as medidas especiais tomadas com o único objetivo de assegurar progresso adequado de certos grupos raciais ou étnicos ou de indivíduos que necessitem da proteção que possa ser necessária para proporcionar a tais grupos ou indivíduos igual gozo ou exercício de direitos humanos e liberdades fundamentais, contando que, tais medidas não

\footnotetext{
${ }^{16} \mathrm{O}$ Brasil foi o último país americano a abolir a escravidão.

17 Nesse sentido que o Estatuto da Igualdade Racial, no artigo $4^{\circ}$, parágrafo único, deixa nítido que “os programas de ação afirmativa constituir-se-ão em políticas públicas destinadas a reparar as distorções e desigualdades sociais e demais práticas discriminatórias adotadas, nas esferas pública e privada, durante o processo de formação social do País" (BRASIL, 2010).
}

Rev. de Movimentos Sociais e Conflitos | e-ISSN: 2525-9830 | Porto Alegre | v. 4 | n. 2 | p. 01 - 22 | Jul/Dez. 2018 
conduzam, em conseqüência, à manutenção de direitos separados para diferentes grupos raciais e não prossigam após terem sidos alcançados os seus objetivos.

Tal entendimento é compatível com a Constituição brasileira de 1988. De fato, o seu preâmbulo repele o preconceito; o artigo $1^{\circ}$, inciso III, exalta a dignidade da pessoa humana; o artigo $3^{\circ}$, inciso IV, veda o preconceito racial e qualquer forma de discriminação negativa; o $\operatorname{artigo} 4^{\circ}$, inciso VIII, repudia o racismo nas relações internacionais; o artigo $5^{\circ}$, inciso XLII, criminaliza a prática do racismo; e o artigo $7^{\circ}$, inciso XXX, proíbe a diferença de salários, de exercícios de funções e de critérios de admissão em razão da cor.

Igualmente, o Estatuto da Igualdade Racial se propõe, na dicção de seu artigo $1^{\circ}$, caput, "a garantir à população negra a efetivação da igualdade de oportunidades, a defesa dos direitos étnicos individuais, coletivos e difusos e o combate à discriminação e às demais formas de intolerância étnica" (BRASIL, 2010). Para tal desiderato, incumbe ao Estado e à sociedade garantir à população negra a igualdade de oportunidades e o direito à participação em todos os setores sociais (artigo $2^{\circ}$ ), bem como "adota como diretriz político-jurídica a inclusão das vítimas de desigualdade étnico-racial, a valorização da igualdade étnica e o fortalecimento da identidade nacional brasileira" (artigo $3^{\circ}$ ).

Especificamente quanto às ações afirmativas, a Lei no 12.711, de 29 de agosto de 2012, “dispõe sobre o ingresso nas universidades federais e nas instituições federais de ensino técnico de nível médio e dá outras providências" (BRASIL, 2012a) ${ }^{18}$. Tal Lei reserva no mínimo 50\% das vagas nas instituições de ensino referidas para os candidatos que tenham cursado integralmente em escolas públicas o ensino fundamental, para o ensino técnico, ou o ensino médio, para o ensino superior.

Metade do percentual dessas vagas deverá ser reservada aos estudantes oriundos de famílias com renda igual ou inferior a 1,5 salário-mínimo per capita. Assim sendo, para a outra metade, basta que o beneficiário tenha cursado integralmente o ensino fundamental ou o ensino médio, conforme o seu caso, em escolas públicas, sendo irrelevante o critério renda ${ }^{19}$.

\footnotetext{
${ }^{18} \mathrm{O}$ artigo $7^{\circ}$ da Lei $\mathrm{n}^{\circ} 12.711 / 2012$, cuja redação foi dada pela Lei $\mathrm{n}^{\circ} 13.409$, de 28 de dezembro de 2016, dispõe que "no prazo de dez anos a contar da data de publicação desta Lei, será promovida a revisão do programa especial para o acesso às instituições de educação superior de estudantes pretos, pardos e indígenas e de pessoas com deficiência, bem como daqueles que tenham cursado integralmente o ensino médio em escolas públicas" (BRASIL, 2012a).

${ }^{19}$ Essa outra metade das vagas pode ser ocupada por pessoas que possuam renda familiar per capita superior a 1,5 salário-mínimo, mas também é possível que estudantes com renda igual ou inferior a tal patamar de renda também ocupem tais vagas.
}

Rev. de Movimentos Sociais e Conflitos | e-ISSN: 2525-9830 | Porto Alegre | v. 4 | n. 2 | p. 01 - 22 |

Jul/Dez. 2018 
Cada uma dessas duas metades deve ser preenchida - se houver candidatos - por autodeclarados pretos, pardos, indígenas e por pessoas com deficiência, em proporção ao total de vagas no mínimo igual à proporção respectiva de pretos, pardos, indígenas e pessoas com deficiência na população da unidade da Federação onde está instalada a instituição, segundo o último censo do IBGE.

Nota-se que ao critério étnico fora associado o critério socioeconômico para a concessão de cotas raciais para o ingresso nas universidades federais e nas instituições federais de ensino técnico. Exigindo-se que os beneficiários tenham cursado integralmente em escolas públicas o ensino médio ou o ensino fundamental, conforme o caso, a lei se dirige àqueles que foram alvos das deficiências do ensino público brasileiro, geralmente o grupo populacional mais pobre. Somado a isso, a reserva de metade das vagas para candidatos pertencentes a famílias de baixa renda per capita evidencia a preocupação legislativa de favorecer os mais desprivilegiados entre os excluídos, isto é, os negros pobres. Tudo isso proscreve os argumentos contrários às ações afirmativas que lhes atribuem o potencial de beneficiar exclusivamente negros que porventura integrem a elite.

Por sua vez, a Lei no 12.990 , de 9 de junho de 2014,

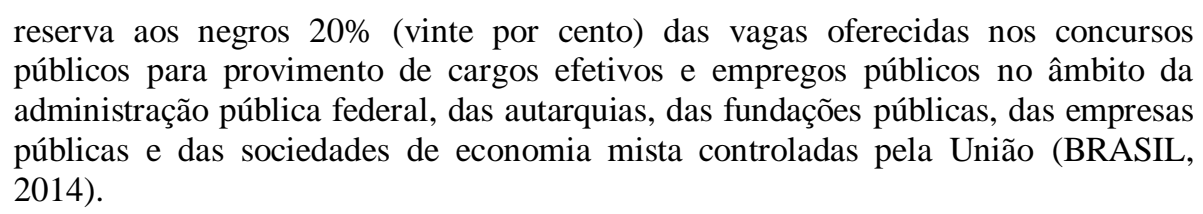

Ambas as leis mencionadas instituem as cotas raciais, espécies do gênero ações afirmativas, cujo objetivo consiste, sucintamente, em "minimizar as desigualdades raciais (no âmbito da educação, emprego ou acesso às esferas públicas, por exemplo) por meio da igualdade material de oportunidades (em contraponto a uma mera igualdade formal)" (RODRIGUES; ROSCHILDT, 2011, p. 135).

Foi nesse sentido o pronunciamento do Supremo Tribunal Federal, ao considerar constitucionais as cotas raciais para o ensino técnico e superior - Arguição de Descumprimento de Preceito Fundamental (ADPF) no 186 (BRASIL, 2012b) - e para o serviço público - Ação Declaratória de Constitucionalidade (ADC) nº 41 (BRASIL, 2017). Em ambos os julgamentos, os Ministros consideraram unanimemente que o sistema de ações afirmativas para negros adotado no Brasil é compatível com a Constituição brasileira.

Rev. de Movimentos Sociais e Conflitos | e-ISSN: 2525-9830 | Porto Alegre | v. 4 | n. 2 | p. 01 - 22 | Jul/Dez. 2018 
Em síntese, o julgamento da ADPF 186 concluiu que a lei de cotas raciais para o ingresso no ensino técnico e superior preconiza a igualdade material e o direito fundamental à educação, e a noção de justiça social transborda a redistribuição de riquezas porque alcança o reconhecimento de uma sociedade multicultural. ${ }^{20}$

E a ADC 41 assentou que os três fundamentos precípuos que embasam a constitucionalidade da lei de cotas raciais para o ingresso no serviço público são: a discriminação positiva em relação aos negros, fundada na superação do racismo estrutural e institucional, está em consonância com o princípio da isonomia e visa à garantia da igualdade material; não há a ofensa aos princípios do concurso público e da eficiência administrativa (não é dispensada aos candidatos a obtenção de uma nota mínima para o ingresso no serviço público e a consideração do critério "etnia" no processo seletivo amplia a eficiência do serviço público pela criação de uma "burocracia representativa"); e observa o princípio da proporcionalidade mesmo diante da existência de cotas para o ingresso no ensino técnico e superior. $^{21}$

Conforme Minhoto (2013), o único argumento consubstancialmente jurídico - os demais são políticos e morais - que atribui a inconstitucionalidade às ações afirmativas é fundamentado na violação do princípio da igualdade. E a diferenciação entre a igualdade material e a igualdade formal permite solucionar essa controvérsia. Além disso, a regra reside na presunção de constitucionalidade das normas infraconstitucionais, enquanto a inconstitucionalidade é a exceção. São necessários argumentos constitucionalmente consistentes para se concluir pela inconstitucionalidade de uma lei, o que não é o caso das ações afirmativas para negros.

Porém, a declaração da constitucionalidade das leis de ações afirmativas para negros não é suficiente para a luta antirracista, haja vista que ela envolve a implementação de políticas de saúde, de educação, de assistência social, de cidadania (GUIMARÃES, 2009; JACCOUD; BEGHIN, 2002). Nessa perspectiva que o Estatuto da Igualdade Racial, no artigo $4^{\circ}$, prescreve as ações estatais que devem ser prioritariamente promovidas para a participação da população negra em igualdade de oportunidades com os demais membros da sociedade. ${ }^{22}$

\footnotetext{
${ }^{20}$ Para mais informações sobre a ADPF 186, vide Brasil (2012b) e Tapajós (2015).

${ }^{21}$ Para mais informações sobre a ADC 41, vide Brasil (2017) e Nonato e Dias (2017).

${ }^{22}$ São elas: "I - inclusão nas políticas públicas de desenvolvimento econômico e social; II - adoção de medidas, programas e políticas de ação afirmativa; III - modificação das estruturas institucionais do Estado para o adequado enfrentamento e a superação das desigualdades étnicas decorrentes do preconceito e da discriminação
} 
Ademais, para combater a injustiça social, Fraser (2006) comenta que é preciso associar a redistribuição econômica - contra a injustiça econômica - e a luta por reconhecimento - contra a injustiça cultural ou simbólica. Isso porque a "raça" é bivalente. Por um lado, a divisão racial do trabalho impõe aos negros ora posições menos remuneradas e desvalorizadas dentro do mercado de trabalho capitalista, ora a exclusão dele, ou seja, a exploração e a marginalização são marcadas pela etnia. Por outro lado, o privilégio concedido aos traços relacionados com o "ser branco" contrapõe-se ao demérito daquilo considerado como pertencente à cultura negra - representações estereotipadas dos negros como criminosos, primitivos, inferiores.

Portanto, a luta antirracista requer tanto a redistribuição quanto o reconhecimento; isoladamente, não são hábeis ao enfrentamento da má distribuição e do não reconhecimento que atinge a população negra. Os antirracistas "devem buscar remédios econômico-políticos que dissolvam a diferenciação 'racial', enquanto buscam também remédios culturais que valorizem a especificidade de coletividades desprezadas" (FRASER, 2006, p. 236). Eis porque novamente se invalida o argumento que legitima somente as ações afirmativas para pobres, e não para negros: o racismo revela-se tanto a má distribuição quanto o não reconhecimento, e a luta antirracista deve enfrentar a injustiça econômica e a injustiça cultural.

As ações afirmativas, nesse contexto, são remédios afirmativos para a injustiça, pois são "remédios voltados para corrigir efeitos desiguais de arranjos sociais sem abalar a estrutura subjacente que os engendra" (FRASER, 2006, p. 237). Mesmo sem atacar diretamente a estrutura racista e racializada da sociedade brasileira - objetivo que seria típico dos remédios transformativos ${ }^{23}$-, as ações afirmativas são um mecanismo constitucional e legítimo de combate à desigualdade racial.

étnica; IV - promoção de ajustes normativos para aperfeiçoar o combate à discriminação étnica e às desigualdades étnicas em todas as suas manifestações individuais, institucionais e estruturais; V - eliminação dos obstáculos históricos, socioculturais e institucionais que impedem a representação da diversidade étnica nas esferas pública e privada; VI - estímulo, apoio e fortalecimento de iniciativas oriundas da sociedade civil direcionadas à promoção da igualdade de oportunidades e ao combate às desigualdades étnicas, inclusive mediante a implementação de incentivos e critérios de condicionamento e prioridade no acesso aos recursos públicos; VII - implementação de programas de ação afirmativa destinados ao enfrentamento das desigualdades étnicas no tocante à educação, cultura, esporte e lazer, saúde, segurança, trabalho, moradia, meios de comunicação de massa, financiamentos públicos, acesso à terra, à Justiça, e outros” (BRASIL, 2010).

23 "Por remédios transformativos, em contraste, entendo os remédios voltados para corrigir efeitos desiguais precisamente por meio da remodelação da estrutura gerativa subjacente. O ponto crucial do contraste [entre os

Rev. de Movimentos Sociais e Conflitos | e-ISSN: 2525-9830 | Porto Alegre | v. 4 | n. 2 | p. 01 - 22 | Jul/Dez. 2018 


\section{CONSIDERAÇÕES FINAIS}

Diante da discriminação racial e do racismo patentes, sustentar a existência da democracia racial é inconcebível e plenamente desvinculada da realidade brasileira. Nesse cenário, as ações afirmativas são mecanismos que buscam a correção das distorções provocadas pela desigualdade racial.

O Direito, nesse contexto, promove a transformação social e situa-se como um mecanismo na luta antirracista, além de trazer à tona o racismo impregnado na sociedade e nas instituições brasileiras. A política de ações afirmativas para negros fomentará o empoderamento crítico pela própria população negra e o potencial emancipatório da educação por meio da aquisição de competência técnica e política institucionalizada, bem como buscará a redução da desigualdade de oportunidades e possibilitará a representatividade do negro nos órgãos estatais.

$\mathrm{Na}$ apreciação do sistema de cotas raciais, é preciso se distinguir dois momentos distintos. É inegável que tais cotas não representam a solução ideal para a eliminação completa da desigualdade racial brasileira (aliás, são remédios afirmativos, e não transformativos). A luta antirracista também deve almejar um território de igualdade racial na sociedade e no Estado, de modo que as cotas raciais sejam desnecessárias.

Contudo, a discriminação positiva que ela propicia abre espaço para a luta contra a opressão sofrida ontem e atualmente pela população negra. Pular etapas, isto é, abolir as cotas raciais, no hodierno estágio histórico brasileiro, baseando-se no mito da democracia racial, significa reforçar e ampliar a desigualdade racial já existente com base em um postulado abstrato que é a meta, mas ainda distante de ser alcançada.

\section{REFERÊNCIAS:}

BENTO, Maria Aparecida Silva. Branquitude e poder: a questão das cotas para negros. In: SANTOS, Sales Augusto dos (Org.). Ações afirmativas e combate ao racismo nas Américas. Brasília: Ministério da Educação, Secretaria de Educação Continuada, Alfabetização e Diversidade, 2005. p. 165-177. (Coleção Educação para Todos, v. 5)

remédios afirmativos e os remédios transformativos] é efeitos terminais vs. processos que os produzem - e não mudança gradual vs. mudança apocalíptica" (FRASER, 2006, p. 237, grifos no original). 
BERTÚLIO, Dora Lucia de Lima. O "novo" Direito velho: racismo e Direito. In: WOLKMER, Antonio Carlos; LEITE, José Rubens Morato (orgs.). Os "novos" direitos no Brasil: natureza e perspectivas: uma visão básica das novas conflituosidades jurídicas. $2^{\mathrm{a}}$ ed. São Paulo: Saraiva, 2012. Cap. 5, p. 125-161.

BRASIL. Decreto-lei no 2.848, de 7 de dezembro de 1940. Código Penal. Rio de Janeiro, 1940.

Decreto $\mathbf{n}^{\mathbf{0}}$ 65.810, de 8 de dezembro de 1969. Promulga a Convenção Internacional sobre a Eliminação de todas as Formas de Discriminação Racial. Brasília, 1969.

Lei $\mathbf{n}^{\mathbf{0}}$ 7.716, de 5 de janeiro de 1989. Define os crimes resultantes de preconceito de raça ou de cor. Brasília, 1989.

Lei no 12.288, de 20 de julho de 2010. Institui o Estatuto da Igualdade Racial; altera as Leis nos 7.716, de 5 de janeiro de 1989, 9.029, de 13 de abril de 1995, 7.347, de 24 de julho de 1985, e 10.778, de 24 de novembro de 2003. Brasília, 2010.

Lei $\mathrm{n}^{0}$ 12.711, de 29 de agosto de 2012. Dispõe sobre o ingresso nas universidades federais e nas instituições federais de ensino técnico de nível médio e dá outras providências. Brasília, 2012a.

Lei $\mathbf{n}^{\mathbf{0}}$ 12.990, de 9 de junho de 2014. Reserva aos negros $20 \%$ (vinte por cento) das vagas oferecidas nos concursos públicos para provimento de cargos efetivos e empregos públicos no âmbito da administração pública federal, das autarquias, das fundações públicas, das empresas públicas e das sociedades de economia mista controladas pela União. Brasília, 2014.

Supremo Tribunal Federal. Ação Declaratória de Constitucionalidade no 41 / DF. Tribunal Pleno. Relator: Luís Roberto Barroso. Julgado em 8 de junho de 2017. Disponível em: <http://redir.stf.jus.br/paginadorpub/paginador.jsp?docTP=TP\&docID=13375729>. Acesso em: 13 ago. 2018.

\section{Supremo Tribunal Federal. Arguição de Descumprimento de Preceito}

Fundamental no 186 / DF. Tribunal Pleno. Relator: Ricardo Lewandowski. Julgado em 26 de abril de 2012b. Disponível em:

<http://redir.stf.jus.br/paginadorpub/paginador.jsp?docTP=TP\&docID=6984693>. Acesso em: 11 ago. 2018.

FERNANDES, Florestan. A integração do negro na sociedade de classes. v. 1. $3^{\mathrm{a}}$ ed. São Paulo: Ática, 1978.

FRANCKLIN, Eugene Oliveira. "Aceitação afro": as mídias sociais digitais na revalorização e afirmação da identidade negra. Juiz de Fora, 2017, 145 p. (Dissertação apresentada à Universidade Federal de Juiz de Fora para a obtenção do título de mestre em Comunicação).

Rev. de Movimentos Sociais e Conflitos | e-ISSN: 2525-9830 | Porto Alegre | v. 4 | n. 2 | p. 01 - 22 |

Jul/Dez. 2018 
FRASER, Nancy. Da redistribuição ao reconhecimento? Dilemas da justiça nua era "póssocialista". Tradução de Julio Assis Simões. Cadernos de Campo. São Paulo, n. 14/15, p. 231-239, 2006.

GOMES, Joaquim B. Barbosa. A recepção do instituto da ação afirmativa pelo Direito Constitucional brasileiro. In: SANTOS, Sales Augusto dos (org.). Ações afirmativas e combate ao racismo nas Américas. Brasília: Ministério da Educação, Secretaria de Educação Continuada, Alfabetização e Diversidade, 2005. p. 45-79. (Coleção Educação para Todos, v. 5)

GOMES, Nilma Lino. Alguns termos e conceitos presentes no debate sobre relações raciais no Brasil: uma breve discussão. In: BRASIL. Educação anti-racista: caminhos abertos pela Lei Federal n ${ }^{\circ}$ 10.639/03. Brasília: Ministério da Educação, Secretaria de Educação Continuada, Alfabetização e Diversidade, 2005. p. 39-62. (Coleção Educação para Todos, v. 2)

GUIMARÃES, Antonio Sérgio Alfredo. Racismo e antirracismo no Brasil. $3^{a}$ ed. São Paulo: Fundação de Apoio à Universidade de São Paulo, Editora 34, 2009.

IBGE. Instituto Brasileiro de Geografia e Estatística. Censo Demográfico 2010: características gerais da população, religião e pessoas com deficiência. Rio de Janeiro: Ministério do Planejamento, Orçamento e Gestão, 2012. Disponível em: <https://biblioteca.ibge.gov.br/visualizacao/periodicos/94/cd_2010_religiao_deficiencia.pdf >. Acesso em: jul. 2018.

JACCOUD, Luciana de Barros; BEGHIN, Nathalie. Desigualdades raciais no Brasil: um balanço da intervenção governamental. Brasília: Instituto de Pesquisa Econômica Aplicada, 2002.

MARTINS, André Ricardo Nunes. Racismo e imprensa: argumentação no discurso sobre as cotas para negros nas universidades. In: SANTOS, Sales Augusto dos (org.). Ações afirmativas e combate ao racismo nas Américas. Brasília: Ministério da Educação, Secretaria de Educação Continuada, Alfabetização e Diversidade, 2005. p. 179-207. (Coleção Educação para Todos, v. 5)

MINHOTO, Antonio Celso Baeta. Da escravidão às cotas: a ação afirmativa e os negros no Brasil. Birigui: Boreal, 2013.

MUNANGA, Kabengele. Identidade, cidadania e democracia: algumas reflexões sobre os discursos anti-racistas no Brasil. Revista Resgate. Campinas, v. 5, n. 1, p. 17-24, 1996.

NONATO, Domingos do Nascimento; DIAS, Daniella Maria dos Santos. Lei de cotas para negros no serviço público federal é constitucional, declara STF. In: XXVI CONGRESSO NACIONAL DO CONPEDI, São Luís, 2017. Anais... Florianópolis, CONPEDI, 2017. p. 237-255. 
RIOS, Roger Raupp. Homofobia na perspectiva dos direitos humanos e no contexto dos estudos sobre preconceito e discriminação. In: JUNQUEIRA, Rogério Diniz (org.).

Diversidade sexual na educação: problematizações sobre a homofobia nas escolas. Brasília: Ministério da Educação, Secretaria de Educação Continuada, Alfabetização e Diversidade, UNESCO, 2009. p. 53-83.

RODRIGUES, Priscila Françoise Vitaca; ROSCHILDT, João Leonardo Marques. Políticas de cotas e a garantia de igualdade de oportunidades: uma equação possível? In: HANDERSON, Joseph; JOSEPH, Francine Pinto da Silva (orgs.). Reflexões sobre a questão racial: cidadania, direito e educação. Pelotas: Editora da UFPel, 2011. p. 129-148.

SANTOS, Boaventura de Sousa. Por uma concepção multicultural de direitos humanos. In: (org.). Reconhecer para libertar: os caminhos do cosmopolitismo multicultural. Rio de Janeiro: Civilização brasileira, 2003. Cap. 9, p. 427-461. (Coleção Reinventar a Emancipação Social: Para Novos Manifestos, v. 3)

SANTOS, Hélio. Ações afirmativas para a valorização da população negra. In:

SARDENBERG, Ronaldo Mota; SANTOS, Hélio. Ações afirmativas para a valorização da população negra. Revista Parcerias Estratégicas. v. 1, n. 4, p. 28-37, dez. 1997.

Discriminação racial no Brasil. In: SABOIA, Gilberto Vergne; GUIMARÃES,

Samuel Pinheiro (orgs.). Anais de Seminários Regionais Preparatórios para Conferência Mundial contra Racismo, Discriminação Racial, Xenofobia e Intolerância Correlata. Brasília: Ministério da Justiça, Secretaria de Estado dos Direitos Humanos, 2001. p. 81-102.

SANTOS, Sales Augusto dos. Movimentos negros, educação e ações afirmativas. Brasília, 2007, 554 p. (Tese apresentada à Universidade de Brasília para a obtenção do título de doutor em Sociologia).

SILVA JR., Hédio. Reflexões sobre a aplicabilidade da legislação anti-racismo. In: SABOIA, Gilberto Vergne; GUIMARÃES, Samuel Pinheiro (orgs.). Anais de Seminários Regionais Preparatórios para Conferência Mundial contra Racismo, Discriminação Racial, Xenofobia e Intolerância Correlata. Brasília: Ministério da Justiça, Secretaria de Estado dos Direitos Humanos, 2001. p. 61-80.

TAPAJÓS, Ib Sales. A política de cotas para negros no ensino superior e o princípio da igualdade. In: XXIV CONGRESSO NACIONAL DO CONPEDI, Belo Horizonte, 2015. Anais... Florianópolis, CONPEDI, 2015. p. 465-494. 